\title{
Comparison of Clinical and Radiological Outcomes of Lumbar Interbody Fusion Using a Combination of Hydroxyapatite and Demineralized Bone Matrix and Autografts for Lumbar Degenerative Spondylolisthesis
}

\author{
Asrafi Rizki Gatam ${ }^{1}$, Luthfi Gatam ${ }^{1}$, Singkat Dohar Lumban Tobing ${ }^{2}$ \\ ${ }^{1}$ Department of Orthopaedic and Traumatology, Fatmawati General Hospital, South Jakarta, Indonesia \\ ${ }^{2}$ Department of Orthopaedic and Traumatology, Cipto Mangunkusumo National Central Hospital and Faculty of Medicine University of Indonesia, \\ Central Jakarta, Indonesia
}

Study Design: Prospective, cohort, non-inferiority study.

Purpose: This study evaluated the clinical and radiological outcomes of interbody fusion using a combination of demineralized bone matrix (DBM) and hydroxyapatite (HA).

Overview of Literature: The use of autografts remains a gold standard in lumbar interbody fusion, but the limited availability and donor site morbidity encourages the use of bone substitutes. In addition to autografts, a combination of HA and DBM is being increasingly use for lumbar interbody fusion. However, there are no data on the clinical and radiological outcomes of this procedure.

Methods: We examined 35 patients with lumbar degenerative spondylolisthesis who underwent transforaminal interbody fusion. Autografts were used in 18 patients, and 17 patients received a combination of HA and DBM. Clinical outcomes were evaluated using the visual analog scale (VAS) for back and leg pain, Oswestry disability index (ODI), and Japanese Orthopaedic Association (JOA) scores at 3, 6, and 12 months postoperatively. Fusion was evaluated using computed tomography images obtained at 12 months postoperatively.

Results: The mean ODI, JOA, and back and leg pain VAS scores increased significantly in both groups. However, the VAS, JOA, and ODI scores did not differ significantly between the two groups ( $p=0.599, p=0.543$, and $p=0.780$, respectively). The fusion rates at 1 year postoperatively were $77.8 \%$ and $76.5 \%$ in the autograft and HA+DBM groups, respectively ( $p=0.99$ ).

Conclusions: The clinical and radiological outcomes of using a combination of HA and DBM in lumbar interbody fusion were not inferior to those of using autografts. A combination of HA and DBM can be considered as an alternative in patients with lumbar degenerative spondylolisthesis requiring surgery.

Keywords: Lumbar; Spine fusion; Bone matrix; Hydroxyapatite; Lumbar degenerative spondylolisthesis

Received Sep 29, 2016; Revised Feb 14, 2017; Accepted Mar 12, 2017

Corresponding author: Asrafi Rizki Gatam

Department of Orthopaedic and Traumatology, Fatmawati General Hospital, Jl. Keuangan IV/59B, Jakarta Selatan DKI, South Jakarta 12430, Indonesia

Tel: +62217660616, Fax: +62217660616, E-mail: rizki.gatam@gmail.com 


\section{Introduction}

Considering that pain can be relieved with good arthrodesis, lumbar fusion is one of the most commonly used procedures in patients with lumbar degenerative spondylolisthesis $[1,2]$. Several studies have shown that the clinical outcomes of this procedure are usually associated with good bone fusion between two vertebrae [3-5]. For achieving fusion, autografts are still the gold standard owing to their potential for osteoconductivity, osteoinductivity, and osteogenicity [6]. Despite their high potential, autografts have limitations such as limited availability and donor site morbidity [3]. Furthermore, disruption in the performance of daily activities and discomfort while walking have been reported [7].

To overcome the limitations of autografts, the use of bone substitutes has increased, although there are no substitutes having properties similar to autografts [8]. A combination of several bone substitutes has been used mainly for achieving spinal fusion. Demineralized bone matrix (DBM) is an allogenic bone substitute comprising bone morphogenic protein, collagen, protein, and growth factors such as transforming growth factor and insulin growth factor [9]. Therefore, it has both osteoinductive and osteoconductive capacities and can promote bone healing through growth factors, which initiate mesenchymal cell differentiation into osteoblasts [6]. Hydroxyapatite (HA) is frequently used as an autograft extender and has osteoconductive properties. A previous study has shown comparable result to autograft [3].

Several animal studies have compared a combination of DBM and HA with autografts and demonstrated comparable results [10]. Research conducted by Tilkeridis et al. [11] on posterolateral fusion revealed no statistically significant differences between autografts and DBM. Miyazaki et al. [8] stated that DBM exhibited a 75\% fusion rate. The use of different DBM brands has also exhibited variable results. This study evaluated the clinical and radiological outcomes of using a combination of DBM and HA for interbody fusion.

\section{Materials and Methods}

We conducted a prospective, cohort, non-inferiority study

Table 1. Demographic and clinical characteristic

\begin{tabular}{|c|c|c|c|c|}
\hline Variable & Autograft $(n=18)$ & $\mathrm{DBM}+\mathrm{HA}(\mathrm{n}=17)$ & Mean difference $(95 \% \mathrm{CI})$ & $p$-value \\
\hline Age (yr) & $57.6 \pm 6.13$ & $53.1 \pm 11.31$ & $4.5(-1.9$ to 10.9$)$ & 0.160 \\
\hline Sex & & & & 0.130 \\
\hline Male & $6(37.5)$ & $10(62.5)$ & & \\
\hline Female & $12(63.2)$ & $7(36.8)$ & & \\
\hline $\mathrm{BMI}\left(\mathrm{kg} / \mathrm{m}^{2}\right)$ & $24.8 \pm 3.42$ & $23.6 \pm 3.67$ & $1.2(-1.2$ to 3.7$)$ & 0.319 \\
\hline BMl category & & & & 0.494 \\
\hline Normal & $6(40.0)$ & $9(60.0)$ & & \\
\hline Overweight & $4(66.7)$ & $2(33.3)$ & & \\
\hline Obese & $8(57.1)$ & $6(42.9)$ & & \\
\hline Smoking history & & & & 0.227 \\
\hline Yes & $4(36.4)$ & $7(63.6)$ & & \\
\hline No & $14(58.3)$ & $10(41.7)$ & & \\
\hline Hemoglobin praoperasi (g/dL) & $12.7 \pm 2.05$ & $12.3 \pm 1.20$ & $0.3(-0.8$ to 1.5$)$ & 0.574 \\
\hline Operation level & & & & 0.586 \\
\hline L3-4 & $1(25.0)$ & $3(75.0)$ & & \\
\hline L4-5 & $15(53.6)$ & $13(46.4)$ & & \\
\hline L5-S1 & $2(66.7)$ & $1(33.3)$ & & \\
\hline Intraoperative bleeding, median (IQR) (mL) & $800(400$ to 1,125$)$ & 300 (225 to 400$)$ & 400 (189 to 700$)$ & 0.001 \\
\hline
\end{tabular}

Values are presented as mean \pm standard deviation or number (\%) unless otherwise indicated.

DBM, demineralized bone matrix; $\mathrm{HA}$, hydroxyapatite; $\mathrm{Cl}$, confidence interval; BMI, body mass index; IQR, interquartile range. 
of patients with lumbar degenerative spondylolisthesis who underwent transforaminal interbody fusion (TLIF) between July 2014 and January 2015. The patients who underwent TLIF using autografts or a combination of DBM and HA were followed up. The DBM used in this study was from Bongener (Daewoong, Seoul, Korea) and HA was from Bongros-HA (Daewoong). Bongener (Daewoong) is a combination of DBM and a blood-controlled thermoresponsive polymer with effective osteoinductive properties. Bongros-HA (Daewoong) is a type of ceramic or bone-chip synthetic material made of porous HA $\left(\mathrm{Ca}_{10}\left(\mathrm{PO}_{4}\right)_{6}(\mathrm{OH})_{2}\right)$, which is usually used as a bone graft extender; the particle size ranges from 3.0 to $6.0 \mathrm{~mm}$. In our 6-month study period, 65 patients fulfilled the inclusion criteria but 10 patients refused participation. Of the remaining 55 patients, 27 and 28 patients were operated using autografts and a combination of DBM and HA, respectively. In each group, nine patients were lost to follow-up at 1 year. Patient characteristics in both groups exhibited similar age and sex distributions, operation levels, and body mass indices (Table 1).

\section{Surgical procedures}

All patients underwent single-level TLIF, which was performed in a standard manner as previously reported [12]. The polyetheretherketone cages were filled with either an autograft or a combination of DBM and HA (Fig. 1). Foraminectomy was conducted on the side with most severe clinical signs and symptoms.

\section{Clinical and radiological outcomes}

Clinical outcomes were evaluated using the visual analog scale (VAS) for back and leg pain, the Oswestry disability index (ODI), and the Japanese Orthopaedic Association (JOA) score. All the outcomes were assessed preoperatively and at 3,6, and 12 months postoperatively. The fusion rate was determined using the criteria reported by Girasole et al. [12], which was applied by a musculoskeletal radiologist (Table 2). Fusion was indicated by a score of 3 or 4 . The maintenance of fusion sites was evaluated based on the occurrence of subsidence and the lordotic angles at
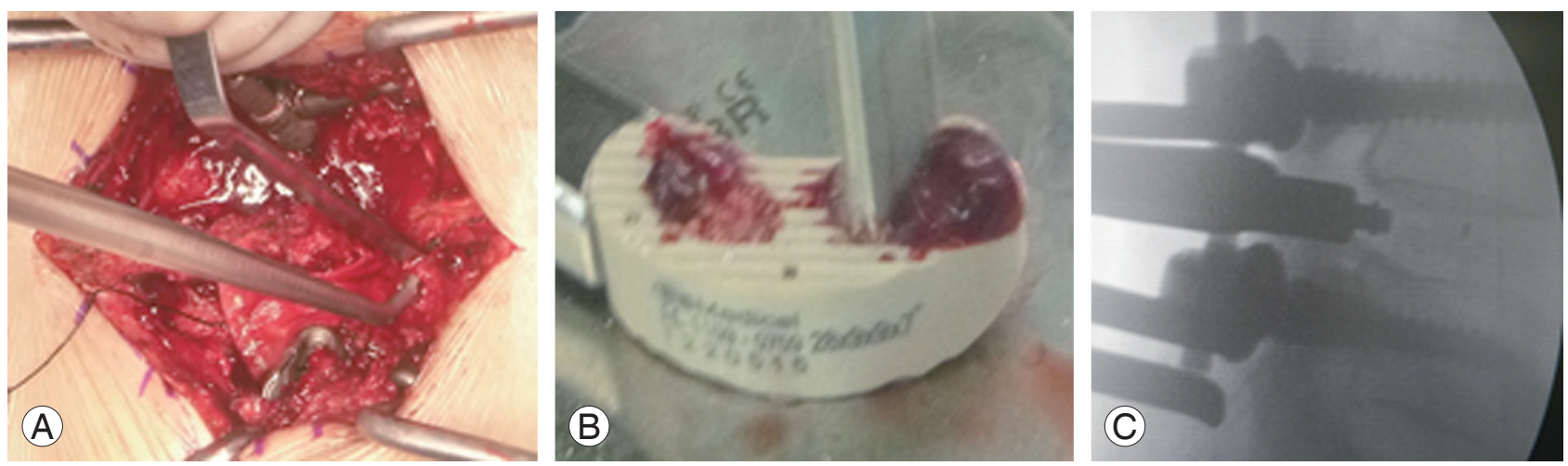

Fig. 1. Operative procedure. (A) Intraoperative view of posterior foraminectomy and discectomy. (B) Preparation for implanting demineralized bone matrix and hydroxyapatite into the cage. (C) Intraoperative image obtained after the cage was inserted anteriorly.

Table 2. Gisole grading system

\begin{tabular}{lcl} 
Radiologic evaluation & Points & \multicolumn{1}{c}{ Remarks } \\
\hline Spacer margin & 0 & Any evidence of subsidence or lucency around the cage \\
\hline Bone within cage & 1 & Tightly marginated with both endplates without bone resorption or subsidence \\
& 0 & $\begin{array}{l}\text { Lucency within cage similar to nonossified disc } \\
\text { Increased density within spacer beyond that of nonossified disc space suggestive of } \\
\text { trabecular bone }\end{array}$ \\
\hline Bone bridge between endplates & 1 & No bony bridging between endplates \\
& 1 & $<0.5 \mathrm{~cm}$ bridge on either sagittal or coronal reconstruction \\
\hline
\end{tabular}


1 year postoperatively.

\section{Statistical analysis}

All research data were evaluated using SPSS ver. 17 (SPSS Inc., Chicago, IL, USA). Numerical data were analyzed using the Mann-Whitney $U$ (non-parametric statistic) test, and proportion data were analyzed using the Fisher exact test.

\section{Ethical approval}

Ethical approval for this research was provided by the Ethical Research Committee of Ciptomangunkusumo National Reference Hospital, Faculty of Medicine, Universitas Indonesia.

\section{Results}

Overall, 35 patients were followed up until 1 year. The median preoperative back and leg pain VAS score in the autograft and combination groups was 6 (5-7) out of 10 , and the scores in both groups showed a decreasing trend on follow-up. At 3, 6, and 12 months postoperatively, the back VAS scores were $2(2-3.3), 2(1-3)$, and $1(0-2)$ in the autograft group and $2(1.5-3), 2(1-2)$, and 1 in the combination group, respectively (all $p>0.05$ ). The median leg pain VAS scores at 3, 6, and 12 months postopera- tively were 6 (5-6.3), $4(3-4)$, and $2(1-3)$ in the autograft group and 5 (5-7), $3(3-3)$, and $1(0-1)$ in the combination group, respectively. The leg pain VAS scores showed significant differences between the two groups at 6 and 12 months postoperatively ( $p=0.001$ and $p=0.003$, respectively) (Table 3).

The median preoperative ODI score was 62 (56.5-70.5) in the autograft group and 58 (52-63.5) in the combination group; on follow-up, the scores showed significant improvement in both groups. In the autograft group, the scores at 3,6, and 12 months postoperatively were 12 (5.5-14.5), 8 (4-12.5), and $5.5(1.5-10)$ in the autograft group and 16 (8-32.5), $12(4-19)$, and $10(3.5-17.5)$ in the combination group, respectively. There were no significant differences between the two groups (Table 4).

The JOA score did not significantly differ between the autograft and combination groups. Both groups showed significant improvement in the scores until 12 months postoperatively. The scores increased from 9.5 (7.8-12) preoperatively to $27(25-28)$ at 12 months postoperatively in the autograft group and from $11(8.5-14)$ to 26 (24.527.5 ) in the combination group (Table 5).

The fusion rates at 1 year were $77.8 \%$ in the autograft group and $76.5 \%$ in the combination group $(p=0.99)$. Among the study population, $8.6 \%$ exhibited a fusion grade I; $14.3 \%$, grade II; $40 \%$, grade III; and $37.1 \%$, grade IV. Among patients with fusion grades III and IV, solid bony bridging between two vertebral bodies in both the

Table 3. Comparison of visual analog scale between autograft and combination of DBM+HA

\begin{tabular}{|c|c|c|c|c|}
\hline Visual analog scale & Autograft $(\mathrm{n}=18)$ & $\mathrm{DBM}+\mathrm{HA}(\mathrm{n}=17)$ & Median difference $(95 \% \mathrm{Cl})$ & $p$-value \\
\hline \multicolumn{5}{|l|}{ Back } \\
\hline Preoperative & 6 (5 to 7$)$ & 6 (5 to 7$)$ & $0(-1$ to 1$)$ & 0.708 \\
\hline \multicolumn{5}{|l|}{ Postoperative } \\
\hline $3 \mathrm{mo}$ & 2 (2 to 3.3 ) & 2 (1.5 to 3 ) & $0(-1$ to 1$)$ & 0.613 \\
\hline $6 \mathrm{mo}$ & 2 (1 to 3 ) & 2 (1 to 2) & $0(-1$ to 1$)$ & 0.660 \\
\hline $12 \mathrm{mo}$ & 1 (0 to 2) & 1 (0 to 1.5$)$ & $0(0$ to 1$)$ & 0.386 \\
\hline \multicolumn{5}{|l|}{ Leg } \\
\hline Preoperative & $6(5.8$ to 7$)$ & 6 (6 to 7$)$ & $0(-1$ to 1$)$ & 0.909 \\
\hline \multicolumn{5}{|l|}{ Postoperative } \\
\hline $3 \mathrm{mo}$ & 6 (5 to 6.3$)$ & 5 (5 to 6$)$ & $0(0$ to 1$)$ & 0.143 \\
\hline $6 \mathrm{mo}$ & 4 (3 to 4) & 3 (3 to 3) & $1(0$ to 1$)$ & 0.001 \\
\hline $12 \mathrm{mo}$ & 2 (1 to 3) & $1(0$ to 1$)$ & 1 (0 to 2) & 0.003 \\
\hline
\end{tabular}

Values are presented as median (IQR). A $p$-value was evaluated using Mann-Whitney non-parametric measurement. Median difference and $95 \%$ confidence interval were estimated using Hodges-Lehman method.

DBM, demineralized bone matrix; $\mathrm{HA}$, hydroxyapatite; $\mathrm{Cl}$, confidence interval; IQR, interquartile range. 
Table 4. Comparison of Oswestry Disability Index between autograft and combination of DBM+HA

\begin{tabular}{|c|c|c|c|c|}
\hline Oswestry disability index & Autograft $(\mathrm{n}=18)$ & $\mathrm{DBM}+\mathrm{HA}(\mathrm{n}=17)$ & Median difference (Cl 95\%) & $p$-value \\
\hline Preoperative & 62 (56.5 to 70.5 ) & 58 (52 to 63.5) & $6(-2$ to 14$)$ & 0.103 \\
\hline \multicolumn{5}{|l|}{ Postoperative } \\
\hline $3 \mathrm{mo}$ & 12 (5.5 to 14.5$)$ & 16 (8 to 32.5 ) & $-4(-12$ to 2$)$ & 0.232 \\
\hline $6 \mathrm{mo}$ & $8(4$ to 12.5$)$ & $12(4$ to 19$)$ & $-2(-8$ to 4$)$ & 0.483 \\
\hline $12 \mathrm{mo}$ & $5.5(1.5$ to 10$)$ & 10 (3.5 to 17.5$)$ & $-3(-10$ to 2$)$ & 0.184 \\
\hline
\end{tabular}

Values are presented as median (IOR). A $p$-value was evaluated using Mann-Whitney non parametric measurement; Median difference and confidence interval 95\% were estimated using Hodges-Lehman method.

DBM, demineralized bone matrix; HA, hydroxyapatite; $\mathrm{Cl}$, confidence interval; IQR, interquartile range.

Table 5. Comparison of Japanese Orthopaedic Association score between autograft and DBM+HA

\begin{tabular}{|c|c|c|c|c|}
\hline Japanese Orthopaedic Association score & Autograft $(\mathrm{n}=18)$ & $\mathrm{DBM}+\mathrm{HA}(\mathrm{n}=17)$ & Median difference $(95 \% \mathrm{Cl})$ & $p$-value \\
\hline Preoperative & $9.5(7.8$ to 12$)$ & 11 (8.5 to 14) & $-1(-4$ to 1$)$ & 0.287 \\
\hline \multicolumn{5}{|l|}{ Postoperative } \\
\hline $3 \mathrm{mo}$ & 23 (22 to 24) & 24 (21 to 25 ) & -0.5 (-2 to 1$)$ & 0.568 \\
\hline $6 \mathrm{mo}$ & 25.5 (24.8 to 26$)$ & 25 (22 to 25.5) & $1(0$ to 3$)$ & 0.110 \\
\hline $12 \mathrm{mo}$ & 27 (25 to 28 ) & 26 (24.5 to 27.5 ) & 1 (-1 to 2$)$ & 0.351 \\
\hline
\end{tabular}

Values are presented as median (IQR). A $p$-value was evaluated using Mann-Whitney non parametric measurement; Median difference and $95 \%$ confidence interval were estimated using Hodges-Lehman method.

DBM, demineralized bone matrix; $\mathrm{HA}$, hydroxyapatite; $\mathrm{Cl}$, confidence interval; IQR, interquartile range.

Table 6. Radiological outcome of interbody fusion

\begin{tabular}{|c|c|c|c|c|c|}
\hline Variable & Overall $(n=35)$ & Autograft ( $\mathrm{n}=18$ ) & $\mathrm{DBM}+\mathrm{HA}(\mathrm{n}=17)$ & $p$-value & Power (\%) \\
\hline Fusion & $27(77.1)$ & $14(51.9)$ & $13(48.1)$ & 0.99 & 65 \\
\hline Not fusion & $8(22.9)$ & $4(50.0)$ & $4(50.0)$ & & \\
\hline Fusion grading & & & & 0.99 & \\
\hline 1 & $3(8.6)$ & $2(66.7)$ & $1(33.3)$ & & \\
\hline$\|$ & $5(14.3)$ & $2(40.0)$ & $3(60.0)$ & & \\
\hline III & $14(40.0)$ & $7(50.0)$ & $7(50.0)$ & & \\
\hline IV & 13 (37.1) & $7(53.8)$ & $6(46.2)$ & & \\
\hline
\end{tabular}

Values are presented as number (\%). A $p$-value was calculated using exact Fisher test; Statistic test value was calculated for non-inferiority hypothesis with parametric test for two independent proportion.

DBM, demineralized bone matrix; HA, hydroxyapatite.

autograft and combination groups (Table 6), minimal subsidence of $<2 \mathrm{~mm}$, and maintenance of the lordotic angle at 1 year postoperatively $(p<0.05)$ were observed. In the non-fusion group, subsidence of $>4 \mathrm{~mm}$ and loss of the lordotic angle were observed, indicating fixation failure, which results in sagittal imbalance $(p<0.05)$ (Tables $7-9)$.

\section{Discussion}

Lumbar interbody fusion surgery is a procedure for the management of lumbar degenerative spondylolisthesis, and this procedure can be performed with or without instrumentation [1]. The goal is to achieve solid bony fusion between vertebral bodies. Autografts from the iliac crest were previously the gold standard; however, several studies are recently evaluating the use of local bone chips obtained from laminectomy [13,14]. Hashimoto et al. [15], Ido et al. [16] and Miura et al. [17] and have reported that local bone chips had fusion rates of approximately $70 \%$, which is lower than the fusion rate (85\%-95\%) achieved 
using iliac crest autografts [15-18].

Several studies on bone substitutes have been conducted. Khan et al. [13] and Grabowski and Cornett [4] compared the use of autografts, autograft+DBM, and DBM alone in posterolateral fusion and reported no significant differences. Using animal models, Smucker and Fredericks [19] and Lee et al. [20] demonstrated similar histologically mature bone formation in both autograft and DBM groups after posterolateral fusion. In South Korea, Lee et al. [21] used DBM in direct lateral lumbar interbody

\section{Table 7. Cage variables}

\begin{tabular}{lc} 
Variable & \multicolumn{1}{l}{ Value } \\
\hline Inserted level & \\
\hline L3-4 & $4(11.4)$ \\
L4-5 & $28(80)$ \\
\hline L5-S1 & $3(8.5)$ \\
\hline Cage height (mm) & $5(14.2)$ \\
\hline 10 & $26(74.2)$ \\
\hline 12 & $4(11.4)$ \\
\hline 14 & \\
\hline Lordotic angle & $11.5 \pm 1.7$ \\
\hline Directly postoperation & $10.8 \pm 2.1$ \\
\hline 1 Year postoperation
\end{tabular}

Values are presented as number (\%) or mean \pm standard deviation.

Table 8. Cage subsidence variables after 1 year

\begin{tabular}{lcc} 
& \multicolumn{2}{c}{ Direction } \\
\cline { 2 - 3 } Subsidence depth $(\mathrm{mm})$ & Superior & Inferior \\
\cline { 2 - 3 } & $20(57.3)$ & $7(20)$ \\
$2-4$ & $4(11.4)$ & $2(5.7)$ \\
$>4$ & $1(2.8)$ & $1(2.8)$ \\
\hline
\end{tabular}

Values are presented as number (\%). fusion and reported a $60.9 \%$ fusion rate at 6 months and $87.5 \%$ at 12 months postoperatively. In this study, computed tomography images obtained at 12 months postoperatively revealed a fusion rate of $76.5 \%$ in the DBM+HA group, with bony bridging that appeared to be solid in coronal and sagittal views (Fig. 2). Two patients from the $\mathrm{DBM}+\mathrm{HA}$ group and one from the autograft group were diagnosed with non-union, but the remaining patients in the non-fusion group were still followed up owing to signs of slow fusion progression (Fig. 3).

Clinical outcomes of lumbar degenerative spondylolisthesis are dependent on the fusion rate. Kasliwal and Deutsch [1] showed a decrease in VAS scores of $>50 \%$ at 14 months postoperatively. Lee et al. [18] also reported good postoperative ODI and VAS scores compared with preoperative scores. In our study, the postoperative VAS scores for back pain decreased significantly in both groups; however, the scores indicated residual leg pain in the autograft group (Figs. 4, 5). According to Hunt et al. [22] residual leg pain can be caused by excessive dural retraction, mobilization of the dura mater, and distraction on the decompression side, which can lead to compression of the contralateral foramen and excessive lumbar lordosis correction $[23,24]$.

In this study, the JOA score showed a $50 \%-60 \%$ in-
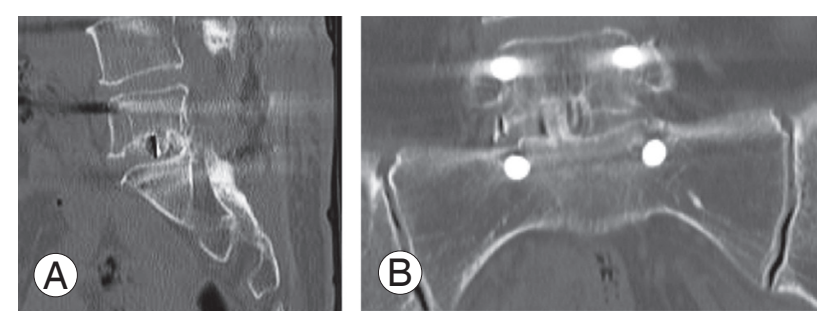

Fig. 2. Computed tomography images obtained at 12 months postoperatively in the demineralized bone matrix+hydroxyapatite group. Sagittal view (A) and coronal view (B); both images show solid bony bridging between two vertebral bodies.

Table 9. Comparison of fusion grade and maintenance of fusion site

\begin{tabular}{|c|c|c|c|c|c|}
\hline \multirow{2}{*}{ Fusion grading } & \multirow{2}{*}{ Subsidence (mm) } & \multirow{2}{*}{$p$-value } & \multicolumn{2}{|c|}{ Lordotic angle } & \multirow{2}{*}{$p$-value } \\
\hline & & & Directly after operation & 1 yr after operation & \\
\hline I & 4.1 & 0.075 & 11.3 & 9.2 & 0.081 \\
\hline$\|$ & 2.13 & & 11.8 & 10.3 & \\
\hline III & 0.58 & & 11.5 & 11.5 & \\
\hline IV & 0.56 & & 11.6 & 11.5 & \\
\hline
\end{tabular}

Values are presented as mean. A $p$-value was calculated with chi-square tests. 


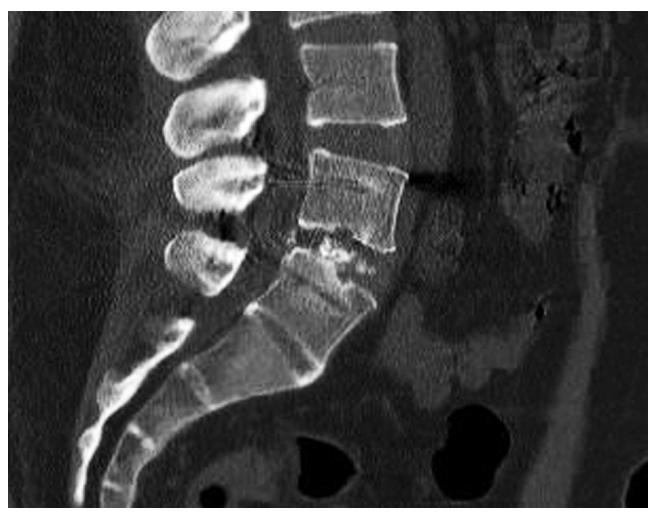

Fig. 3. Sagittal computed tomography images obtained at 12 months postoperatively in the demineralized bone matrix+hydroxyapatite group. Image shows non-union at 12 months postoperatively. The patient underwent revision surgery.

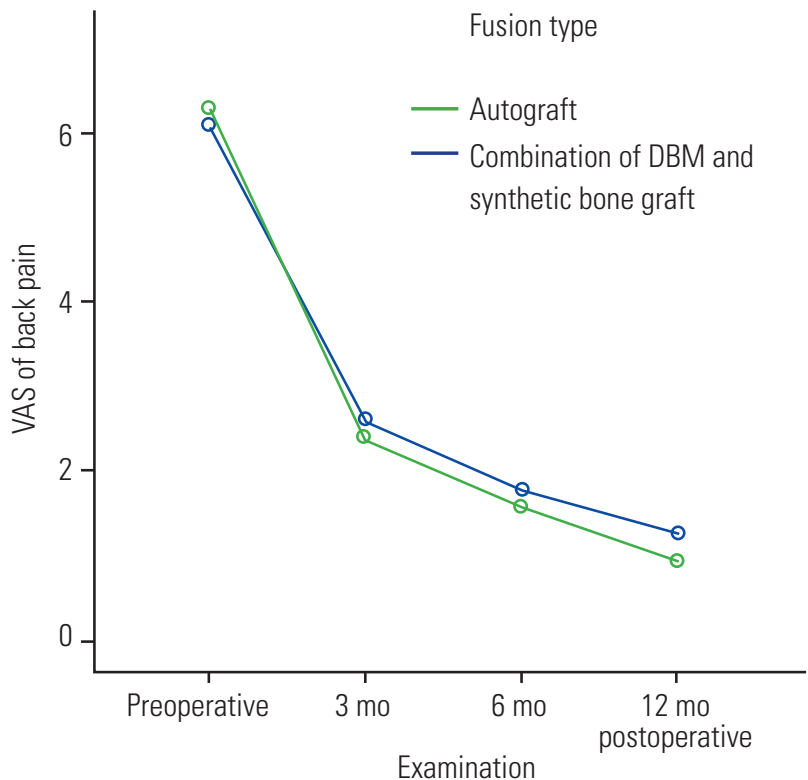

Fig. 4. Comparison of back pain visual analog scale (VAS) scores between the autograft and demineralized bone matrix (DBM)+hydroxyapatite groups.

crease in the fusion (autograft or combination) group, whereas in the non-fusion group, only an increase of $20 \%-30 \%$ was observed (Fig. 6). Significant differences between the fusion and non-fusion groups were also detected. The ODI scores were comparable between the autograft and DBM+HA groups; however, in the non-fusion group, moderate disability was noted at 12 months (Fig. 7). This result is in accordance with that of a previous study showing that an increase in ODI scores is parallel to the extent of fusion and patient satisfaction [25]. Yu et al. [26] stated that good fusion indicates good clinical outcomes in lumbar spondylosis. In addition, Zigler and Delamarter

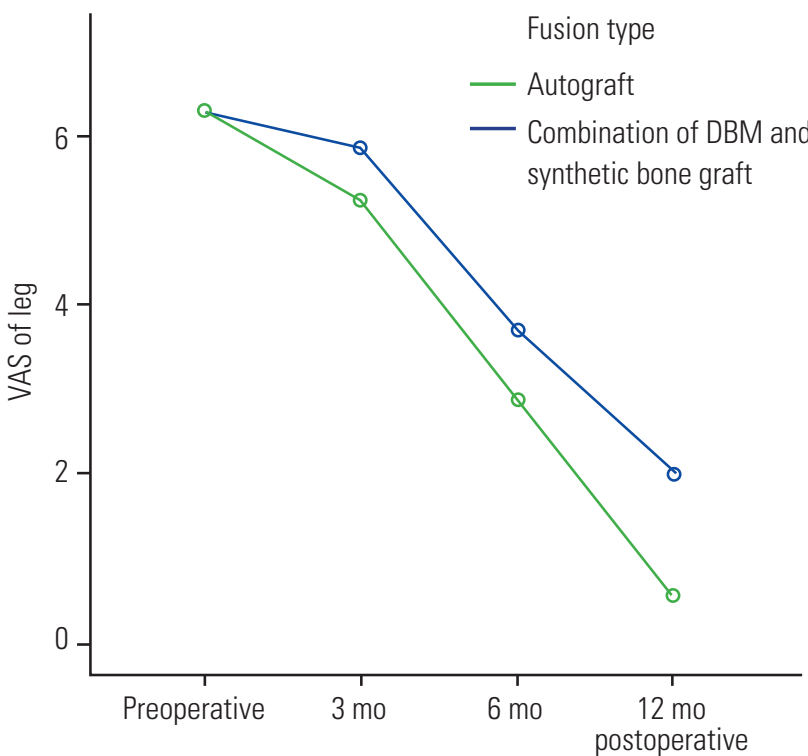

Fig. 5. Comparison of leg pain visual analog scale (VAS) scores between the autograft and demineralized bone matrix (DBM)+hydroxyapatite groups.

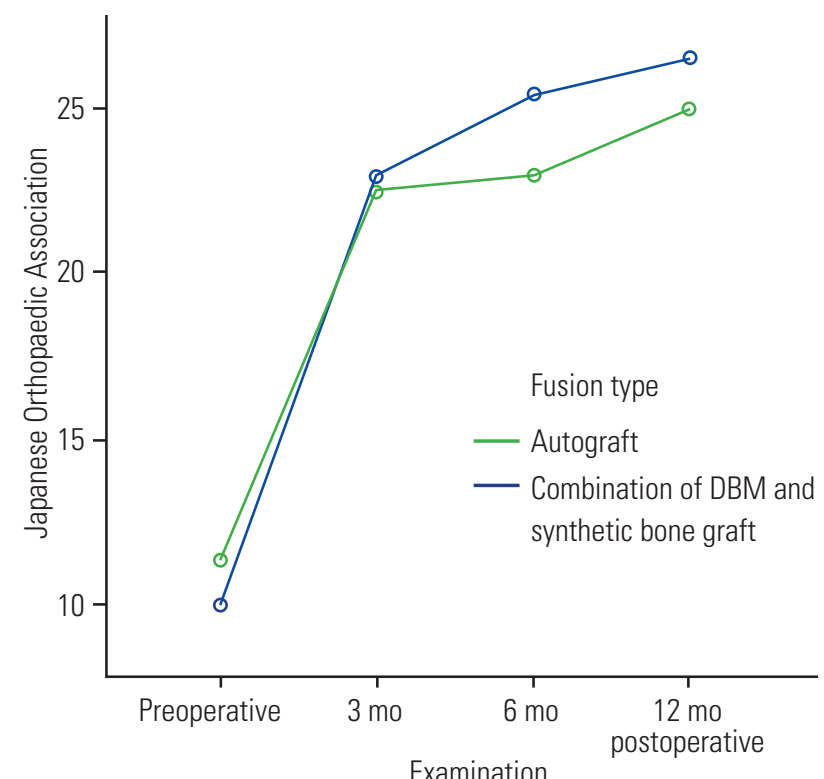

Fig. 6. Comparison of Japanese Orthopaedic Association scores between the autograft and demineralized bone matrix (DBM)+hydroxyapatite groups.

[27] reported that after fusion, patients showed improved quality of life and ability to perform recreational activities.

This study had some limitations, including a limited number of patients and a 12-month follow-up period, which might be too short to precisely evaluate the outcome. Other parameters for evaluating fusion, such as cage subsidence and lumbar lordosis, were not assessed in 


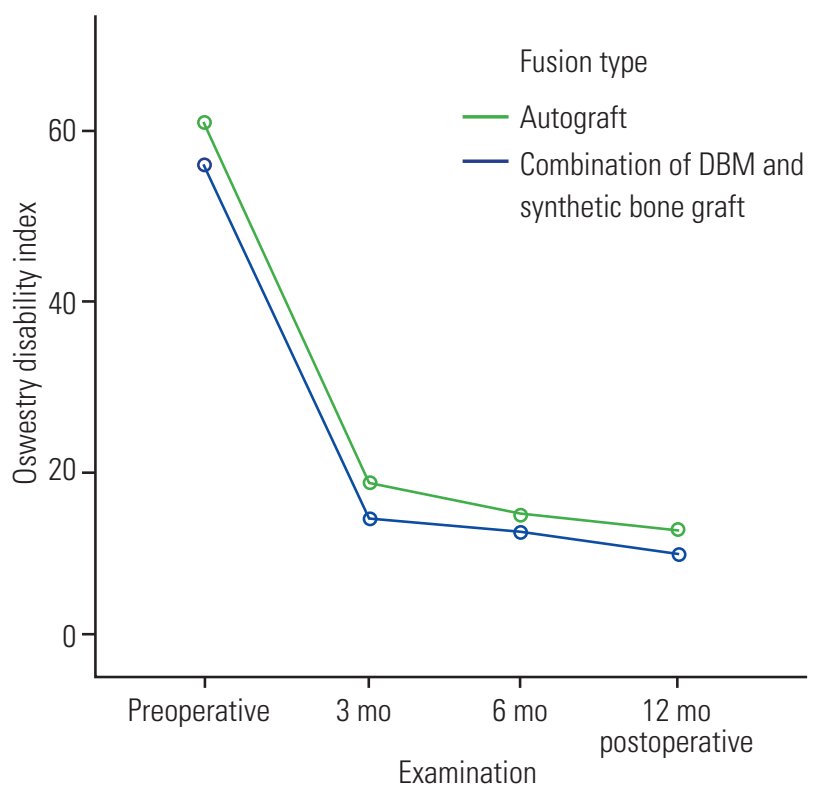

Fig. 7. Comparison of Oswestry disability index scores between the autograft and demineralized bone matrix (DBM)+hydroxyapatite groups.

this study.

\section{Conclusions}

In conclusion, the use of a combination of DBM and HA exhibited clinical and radiological outcomes comparable to those obtained using autografts. Despite being inferior to autografts, bone substitutes comprising $\mathrm{DBM}+\mathrm{HA}$ can be considered as an alternative to autografts. We detected no significant differences between the autograft and combination groups.

\section{Conflict of Interest}

No potential conflict of interest relevant to this article was reported.

\section{References}

1. Kasliwal MK, Deutsch H. Clinical and radiographic outcomes using local bone shavings as autograft in minimally invasive transforaminal lumbar interbody fusion. World Neurosurg 2012;78:185-90.

2. Boos N, Aebi M. Spinal disorders: fundamentals of diagnosis and treatment. Berlin: Elsevier-Saunders; 2008.

3. Huang H, Jiang C, Feng Z, Jiang X. Comparing the process of creeping substitution between allograft bone and local bone grafting in lumbar interbody fusion. Eur Spine J 2014;23:2068-74.

4. Grabowski G, Cornett CA. Bone graft and bone graft substitutes in spine surgery: current concepts and controversies. J Am Acad Orthop Surg 2013;21:5160.

5. Chau AM, Mobbs RJ. Bone graft substitutes in anterior cervical discectomy and fusion. Eur Spine J 2009;18:449-64.

6. Roberts TT, Rosenbaum AJ. Bone grafts, bone substitutes and orthobiologics: the bridge between basic science and clinical advancements in fracture healing. Organogenesis 2012;8:114-24.

7. Schnee CL, Freese A, Weil RJ, Marcotte PJ. Analysis of harvest morbidity and radiographic outcome using autograft for anterior cervical fusion. Spine (Phila Pa 1976) 1997;22:2222-7.

8. Miyazaki M, Tsumura H, Wang JC, Alanay A. An update on bone substitutes for spinal fusion. Eur Spine J 2009;18:783-99.

9. Khoshzaban A, Mehrzad S, Tavakoli V, Keshel SH, Behrouzi GR, Bashtar M. The comparative effectiveness of demineralized bone matrix, beta-tricalcium phosphate, and bovine-derived anorganic bone matrix on inflammation and bone formation using a paired calvarial defect model in rats. Clin Cosmet Investig Dent 2011;3:69-78.

10. Ozturk A, Yetkin H, Memis L, Cila E, Bolukbasi S, Gemalmaz C. Demineralized bone matrix and hydroxyapatite/tri-calcium phosphate mixture for bone healing in rats. Int Orthop 2006;30:147-52.

11. Tilkeridis K, Touzopoulos P, Ververidis A, Christodoulou S, Kazakos K, Drosos GI. Use of demineralized bone matrix in spinal fusion. World J Orthop 2014;5:30-7.

12. Girasole G, Muro G, Mintz A, Chertoff J. Transforaminal lumbar interbody fusion rates in patients using a novel titanium implant and demineralized cancellous allograft bone sponge. Int J Spine Surg 2013;7:e95-100.

13. Khan SN, Fraser JF, Sandhu HS, Cammisa FP Jr, Girardi FP, Lane JM. Use of osteopromotive growth factors, demineralized bone matrix, and ceramics to enhance spinal fusion. J Am Acad Orthop Surg 2005;13:129-37.

14. Audat Z, Moutasem O, Yousef K, Mohammad B. Comparison of clinical and radiological results of 
posterolateral fusion, posterior lumbar interbody fusion and transforaminal lumbar interbody fusion techniques in the treatment of degenerative lumbar spine. Singapore Med J 2012;53:183-7.

15. Hashimoto T, Shigenobu K, Kanayama M, et al. Clinical results of single-level posterior lumbar interbody fusion using the Brantigan I/F carbon cage filled with a mixture of local morselized bone and bioactive ceramic granules. Spine (Phila Pa 1976) 2002;27:25862.

16. Ido K, Asada Y, Sakamoto T, Hayashi R, Kuriyama S. Use of an autologous cortical bone graft sandwiched between two intervertebral spacers in posterior lumbar interbody fusion. Neurosurg Rev 2001;24:119-22.

17. Miura Y, Imagama S, Yoda M, Mitsuguchi H, Kachi H. Is local bone viable as a source of bone graft in posterior lumbar interbody fusion? Spine (Phila Pa 1976) 2003;28:2386-9.

18. Lee YS, Kim YB, Park SW, Chung C. Comparison of transforaminal lumbar interbody fusion with direct lumbar interbody fusion: clinical and radiological results. J Korean Neurosurg Soc 2014;56:469-74.

19. Smucker JD, Fredericks DC. Assessment of Progenix ((R)) DBM putty bone substitute in a rabbit posterolateral fusion model. Iowa Orthop J 2012;32:54-60.

20. Lee JH, Lee KM, Baek HR, Jang SJ, Lee JH, Ryu HS. Combined effects of porous hydroxyapatite and demineralized bone matrix on bone induction: in vitro and in vivo study using a nude rat model. Biomed
Mater 2011;6:015008.

21. Lee YS, Park SW, Kim YB. Direct lateral lumbar interbody fusion: clinical and radiological outcomes. J Korean Neurosurg Soc 2014;55:248-54.

22. Hunt T, Shen FH, Shaffrey CI, Arlet V. Contralateral radiculopathy after transforaminal lumbar interbody fusion. Eur Spine J 2007;16 Suppl 3:311-4.

23. Cole CD, McCall TD, Schmidt MH, Dailey AT. Comparison of low back fusion techniques: transforaminal lumbar interbody fusion (TLIF) or posterior lumbar interbody fusion (PLIF) approaches. Curr Rev Musculoskelet Med 2009;2:118-26.

24. Jang KM, Park SW, Kim YB, Park YS, Nam TK, Lee YS. Acute contralateral radiculopathy after unilateral transforaminal lumbar interbody fusion. J Korean Neurosurg Soc 2015;58:350-6.

25. Little DG, MacDonald D. The use of the percentage change in Oswestry Disability Index score as an outcome measure in lumbar spinal surgery. Spine (Phila Pa 1976) 1994;19:2139-43.

26. Yu CH, Wang CT, Chen PQ. Instrumented posterior lumbar interbody fusion in adult spondylolisthesis. Clin Orthop Relat Res 2008;466:3034-43.

27. Zigler JE, Delamarter RB. Does 360 degrees lumbar spinal fusion improve long-term clinical outcomes after failure of conservative treatment in patients with functionally disabling single-level degenerative lumbar disc disease? Results of 5-year follow-up in 75 postoperative patients. Int J Spine Surg 2013;7:e17. 